\title{
Adaption strategy of up-flow anaerobic sludge blanket reactor on tetracycline stress during tetracycline antibiotic wastewater treatment
}

\author{
Jinfeng Zhang ${ }^{1,2}$, Guanyi Chen ${ }^{1}$, Qin Zhang ${ }^{3}$, Yi Luo ${ }^{4}$, Chunsong $\mathrm{Wu}^{5}$, Songyan Qin $^{3^{\dagger}}$ \\ ${ }^{1}$ School of Environmental Science and Technology, Tianjin University, Tianjin 300072, China \\ ${ }^{2}$ Tianjin Academy of Environmental Sciences, Tianjin 300191, China \\ ${ }^{3}$ Tianjin University of Technology, Tianjin 300384, China \\ ${ }^{4}$ Nankai University, Tianjin 300072, China \\ ${ }^{5}$ Shandong Engineering Research Center of Green and High-Value Marine Fine Chemical, Shandong Woneng Environmental Protection Engineering \\ Technology Co., Ltd. Weifang 261000, China
}

\begin{abstract}
Tetracycline antibiotic wastewater with high chemical oxygen demand (COD) concentration and containing bio-refractory compounds was investigated in a lab-scale up-flow anaerobic sludge blanket (UASB) and anoxic-oxic (A/O) reactor. Specific methanogenic activity (SMA) was determined to reveal the inhibition levels of methane production and volatile fatty acid (VFA) accumulation. The results showed that microorganisms can adapt to tetracycline or oxytetracycline when the concentration of antibiotics is less than $400 \mathrm{mg} / \mathrm{L}$. Acetic acid, propanoic acid, and n-butyric acid accounted for more than $90 \%$ of VFA with increasing antibiotic concentration from $50 \mathrm{mg} / \mathrm{L}$ to $600 \mathrm{mg} / \mathrm{L}$. During the $215 \mathrm{~d}$ of operation, the concentration of tetracycline antibiotic increased from 0 to $95 \mathrm{mg} / \mathrm{L}$, and the COD concentration from 3,500 to 6,500 $\mathrm{mg} / \mathrm{L}$. The average COD and tetracycline antibiotic removal rates of the reactors were maintained above $90 \%$. The methane production of the UASB reactor achieved $0.32 \mathrm{~L} / \mathrm{g}$ COD. VFA accumulation was observed when tetracycline antibiotic concentration increased to $47.5 \mathrm{mg} / \mathrm{L}$. The sludge granule diameter increased from $0-300$ $\mu \mathrm{m}$ to $300-1,500 \mu \mathrm{m}$ during the operation. Rod-shaped and coccus-shaped organisms with pores and internal channels on the granule surface were observed using scanning electron microscopy. In the internal space, methanogenic filamentous bacteria constitute a rock-steady structure.
\end{abstract}

Keywords: Anoxic-oxic, Methane production, Specific methanogenic activity, Tetracycline antibiotic wastewater, Up-flow anaerobic sludge blanket, Volatile fatty acid

\section{Introduction}

In recent years, the release of antibiotics into the environment has caused concern, because antibiotics are bioactive, polar, persistent, and may have harmful effects on human health [1]. Wastewater from the antibiotic pharmaceutical industry contains high concentrations of antibiotics and is an important pathway of antibiotics to the environment [2-4]. Effective control and removal of antibiotics would greatly assist subsequent domestic sewage treatment. However, antibiotics directly inhibit microbial activities; the presence of antibiotics may negatively affect biological wastewater treatment, particularly in the aerobic sludge system because of their

This is an Open Access article distributed under the terms of the Creative Commons Attribution Non-Commercial License (http://creativecommons.org/licenses/by-nc/3.0/) which permits unrestricted non-commercial use, distribution, and reproduction in any medium, provided the original work is properly cited.

Copyright (C) 2022 Korean Society of Environmental Engineers loose structure relative to the anaerobic system. Anaerobic treatment is an alternative for removing these compounds in pharmaceutical industry wastewater because of its high COD content and persistent character [5-8].

Tetracycline (TC) is the second most widely used class of antibiotics after penicillin. TCs exhibit broad-spectrum antimicrobial activity by inhibiting bacterial protein synthesis. Most studies on treating tetracycline wastewater in biological systems have focused on low tetracycline concentrations because of their bacteriostatic action [9]. Zhang et al. [10] reported that a significant influence on the microbial community was observed in sequencing batch reactors when the TC concentration was increased to $100 \mathrm{mg} / \mathrm{L}$.

Received October 28, 2020 Accepted April 08, 2021

${ }^{\dagger}$ Corresponding author

E-mail: qinsongyan@vip.126.com

Tel: +86-022-60214745 Fax: +86-022-60214745

ORCID: 0000-0003-1709-9062 
Typically, microbial activity can be inhibited in TC-containing wastewater due to its toxic nature. This toxicity can reduce COD removal, which is a key process in wastewater treatment systems. Thus, as these bacteria are responsible for pollutant degradation, the toxicity of $\mathrm{TC}$ on the granules should also be investigated.

The up-flow anaerobic sludge blanket (UASB) reactor is known for its high efficiency and flexibility, especially in treating high organic bio-refractory wastewater [11]. A significant advantage of the UASB process is that no support materials are required for the retention of active sludge, which can be achieved through the formation of settled granules [12-15]. Additionally, the compact structure of granule sludge formed by methanogenic bacteria could protect susceptible microorganisms from inhibitory and toxic pollutants, ensuring the high resistance of UASB to biologically toxic compounds [16]. However, reports on the sludge granulation process under antibiotic exposure in the UASB are limited. Qiu et al. [17] applied UASB to pre-treat berberine and evaluated the bacterial community shift with an increase inberberine loading; the dominant species were Acinetobacter sp., Clostridium sp., Propionibacterium $s p$., and Sphingomonas, which played a minor role in sludge granulation, while Methanosarcina and Methanosaeta were quantitatively confirmed to improve granulation. Previous research on UASB has mainly focused on the organic load and COD removal rate. Few studies have considered the resistance of anaerobic granular sludge to antibiotics. Investigating the endurance of the granular sludge to antibiotic substances is essential because it determines the influent loading of the antibiotic substance in the reactor.

In our study, tetracycline wastewater was obtained from a factory in northern China that produces only tetracycline hydrochloride. Worldwide, the tetracycline hydrochloride usage was approximately 4,000 t/a in 2013, of which this factory produced approximately 1,000 tons. Tetracycline hydrochloride is produced through the $\mathrm{HCl}$ acidification, carbamide crystallization, and butanol extraction of the fermentation substance of streptomycin. The complex production process discharges high concentrations of tetracycline remnants and organic recalcitrance. The average COD concentrations of the tetracycline wastewater were 3,500 and $6,500 \mathrm{mg} / \mathrm{L}$, respectively.

In this study, lab-scale UASB and A/O reactors were constructed and operated for $215 \mathrm{~d}$ to evaluate the performance of UASB and $\mathrm{A} / \mathrm{O}$ for treating tetracycline antibiotic wastewater. The concentration of tetracycline antibiotics changed from 0 to $95 \mathrm{mg} / \mathrm{L}$. Methane production, COD removal rate, and VFA accumulation were monitored to evaluate the impact of tetracycline hydrochloride on both reactors [18]. To further reveal the inhibition level of methane production and VFA accumulation at different tetracycline hydrochloride concentrations, SMA experiments were conducted to characterize the methanogenic activity of the anaerobic sludge. Additionally, the diameter and structure of anaerobic sludge granules were characterized to demonstrate the viability of the UASB and $\mathrm{A} / \mathrm{O}$ reactors. The possibility of using UASB and $\mathrm{A} / \mathrm{O}$ as a substitute treatment process in factories to treat tetracycline wastewater was explored.

The aim of this study was to investigate the adaption mechanism of the UASB reactor on the tetracycline stress during the treatment of tetracycline antibiotic wastewater. By monitoring the tetracycline removal, methane production, and VFA accumulation, it was found that the performance of the reactor changed under the continuously increasing tetracycline concentration in tetracycline wastewater. The resistance of sludge to tetracycline was explored through SMA experiments, and the sludge particle structure was analyzed to reveal the adaptation mechanisms of the UASB reactor.

\section{Material and Methods}

\subsection{The Influent of the Reactor}

The influent of the UASB-A/O reactor was a mixture of glucose and tetracycline wastewater in the start-up stage. When the reactor ran steady, glucose was no longer added, that is, the influent of UASB-A/O reactor was all tetracycline wastewater from day 172 to day 215. The influent COD concentration was in the range of $6,000-6,500 \mathrm{mg} / \mathrm{L}$ as the tetracycline concentration changed from 0 to $95.00 \mathrm{mg} / \mathrm{L}$.

Glucose was added as the carbon source supplement and calculated according to the following formula: glucose $1 \mathrm{~g} / \mathrm{L}=1,000$ $\mathrm{mg} / \mathrm{L}$ COD. Tetracycline antibiotic wastewater was the supernatant of the tetracycline antibiotic decoction dregs resolving solution. $\mathrm{NaHCO}_{3}$ was added to the influent to maintain a $\mathrm{pH}$ of approximately 8.0.

\subsection{Tetracycline Antibiotics Stress on Reactors}

The treatment process consisted of UASB and A/O reactors. The reactors were continuously treated with tetracycline wastewater for $215 \mathrm{~d}$. The concentration of tetracycline antibiotics increased in phase from0 to $95.00 \mathrm{mg} / \mathrm{L}$, and the reactor response to tetracycline antibiotic stress was indicated by the change in reactor treatment efficiency. The treatment efficiency was calculated by the removal rate of COD, accumulation rate of volatile fatty acids (VFA), and methane production rate. The sludge particle structure and size were monitored as the tetracycline antibiotic concentration increased. A specific methanogenic activity test was used to assess the ability of UASB sludge particles to adapt to tetracycline antibiotic stress.

\subsection{Specific Methanogenic Activity Test}

The ability of UASB sludge particles to adapt to tetracycline antibiotic stress was established based on a specific methanogenic activity (SMA) test to determine the acute anaerobic inhibition of tetracycline. Brown serum bottles with a volume of $500 \mathrm{~mL}$ (450 mL liquid volume and $50 \mathrm{~mL}$ headspace volume) were used as the apparatus. Anaerobic activated sludge and glucose were added to maintain the volatile suspended solids (VSS) at $5.00 \mathrm{~g} / \mathrm{L}$ and COD at 5,000 mg/L. Cultivated solutions composed of trace elements and nutrients were based on references [19]. $\mathrm{NaHCO}_{3}$ was added to adjust the $\mathrm{pH}$ to 7.5. In this study, tetracycline antibiotics were found to be composed of tetracycline and oxytetracycline. Oxytetracycline is a byproduct of tetracycline hydrochloride production. Hence, tetracycline and oxytetracycline were administered at concentrations of $0,50,200,400$, and 600 $\mathrm{mg} / \mathrm{L}$, respectively. The serum bottles were flushed with nitrogen gas to remove the oxygen. The bottles were stored at $35 \pm 1^{\circ} \mathrm{C}$ and shaken once every $12 \mathrm{~h}$. Methane production was recorded until no methane was produced. When the reaction was complete, 
the cultivated solution was poured into again, and ethane production was recorded after discarding the supernatant liquor. The test was repeated three times, as described above, to investigate the adaptability of microorganisms to tetracycline and oxytetracycline. The three rounds were recorded as I, II, and III, and the test without tetracycline was recorded as the control sample. The COD concentration of the influent was $3,500-6,500 \mathrm{mg} / \mathrm{L}$.

\subsection{Start-up and Operation of Lab-scale UASB and A/O Reactor}

The UASB reactor with an effective volume of $17.70 \mathrm{~L}$ and an $\mathrm{A} / \mathrm{O}$ reactor with an effective volume of $25.0 \mathrm{~L}$ were setup and operated. The reactor was operated in a continuous flow, and $\mathrm{s}$ schematic of the equipment is shown in Fig. 1. The UASB system was inoculated with anaerobic sludge taken from the UASB reactor at the wastewater treatment station of a Chinese herb factory in Tianjin, China. The A/O system was inoculated with aerobic sludge taken from an $\mathrm{A} / \mathrm{O}$ reactor to treat domestic wastewater. The mixed liquor suspended solids (MLSS) concentration of the UASB reactor was $25,000-30,000 \mathrm{mg} / \mathrm{L}$, and that of the $\mathrm{A} / \mathrm{O}$ reactor was $3,500-4,000$ $\mathrm{mg} / \mathrm{L}$. The hydraulic retention time (HRT) of the UASB reactor was $24 \mathrm{~h}$, and that of the $\mathrm{A} / \mathrm{O}$ reactor was $32 \mathrm{~h}$. The temperature of the UASB reactor was maintained at $35 \pm 2^{\circ} \mathrm{C}$, and the $\mathrm{A} / \mathrm{O}$ reactor was maintained at $20-25^{\circ} \mathrm{C}$.

The operation of the UASB and $\mathrm{A} / \mathrm{O}$ reactors included a start-up period of approximately $20 \mathrm{~d}$ for sludge acclimation. Meanwhile, the inlet COD was supplied by glucose at a concentration of 3,500 $\mathrm{mg} / \mathrm{L}$. From $21 \mathrm{~d}$ to $171 \mathrm{~d}$, the inlet COD gradually increased to $6,000-6,500 \mathrm{mg} / \mathrm{L}$ as the tetracycline concentration changed from 0 to $38.00 \mathrm{mg} / \mathrm{L}$. Low concentrations of tetracycline antibiotics were mixed to allow the sludge to adapt to the antibiotics. Finally, from day 172 to day 215, a sequence of four different tetracycline antibiotic concentrations (38.00, 47.50, 63.33, and $95.00 \mathrm{mg} / \mathrm{L}$ ) was experimentally observed. The inlet COD concentration was maintained at 6,000-6,500 $\mathrm{mg} / \mathrm{L}$ during this period.

\subsection{Analytical Methods}

Methane production was determined by measuring the discharged volume. VFA was measured using a gas chromatograph (GC9560, Shanghai, China). Biogas production and VFAs were monitored daily. The diameter and structure of the sludge granules diameter and structure were determined using a laser particle size analyzer (LS 230, Beckman Coulter) and a scanning electron microscope (SU3500, Hitachi), respectively. Tetracycline antibiotic concentrations were monitored using an Ultra Performance Liquid Chromatography-Mass Spectrometer (WATERS, USA). COD was performed following the standard methods [20].

\section{Results and Discussion}

\subsection{UASB-A/0 Reactors Response on the Tetracycline Antibiotics Stress}

\subsubsection{COD removal of the UASB and $A / 0$ reactor}

The reactors were maintained at a steady state for $171 \mathrm{~d}$ before the tetracycline antibiotic stress experiment. The experiment was performed from day 172 to day 215. During the operation, the concentration of tetracycline antibiotics was increased to 38.00 , 47.50, 63.33, $95.00 \mathrm{mg} / \mathrm{L}$ with the influent COD at concentrations in the range of $6,000-6,500 \mathrm{mg} / \mathrm{L}$. The COD removal, methane production rate, and VFA performance of the UASB and A/O reactors are shown in Fig. 2.

COD removal on day 181 increased the COD concentration of the effluent to 2,992 $\mathrm{mg} / \mathrm{L}$. After a period of adaptation, the COD concentration in the effluent gradually decreased to $1,000 \mathrm{mg} / \mathrm{L}$. When the influent of the UASB was tetracycline antibiotic wastewater, the COD removal rate was approximately $70 \%$, which is lower than the COD removal rate of the start-up stage. The COD concentration of the effluent in the A/O reactor increased from $700 \mathrm{mg} / \mathrm{L}$ to $250 \mathrm{mg} / \mathrm{L}$ with an increase in the proportion of tetracycline

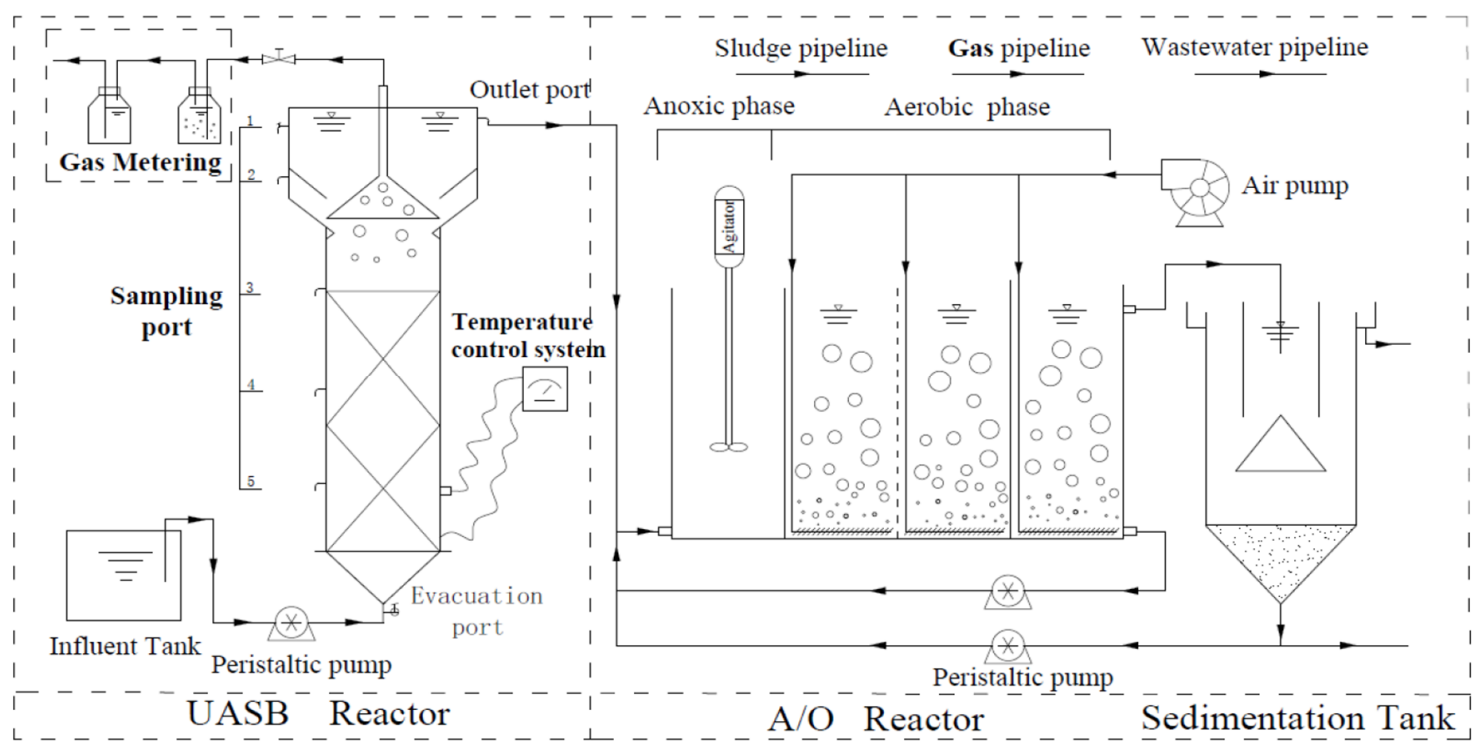

Fig. 1. Schematic diagram of UASB-A/O combined process. 


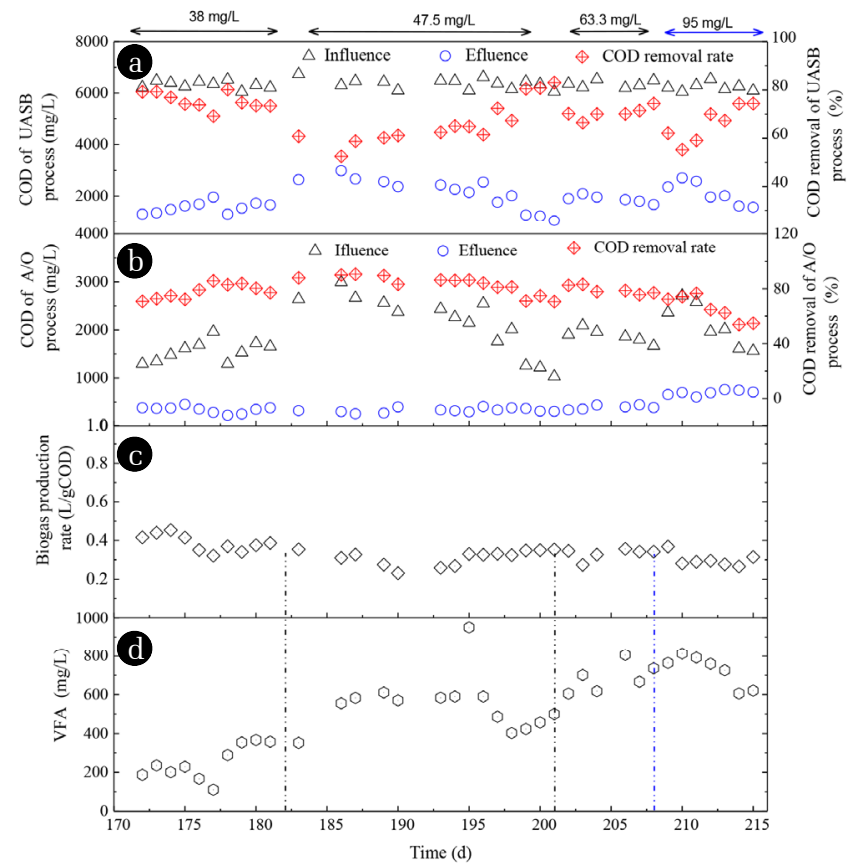

Fig. 2. The performance of the UASB-A/O reactor (a) COD of influent and effluent in the UASB reactor; (b) COD of influent and effluent in the $\mathrm{A} / \mathrm{O}$ reactor; (c) methane production rate; and (d) VFA production in the UASB reactor.

antibiotic wastewater, and the COD removal rate decreased to $54 \%$. Residual antibiotics inhibited anaerobic microorganisms by increasing the proportion of TC wastewater. The activity of acid bacteria and methanogens in anaerobic microorganisms was restored after a period of domestication. Therefore, the COD concentration of the effluent first increased and then decreased. The residue of refractory substances such as benzene rings and amides in wastewater resulted in a dark color of the effluent.

As shown in Fig. 2(a), starting on day 172, tetracycline antibiotic wastewater $(38.00 \mathrm{mg} / \mathrm{L})$ was added to the influent of the UASB to evaluate the influence of tetracycline antibiotics on reactor performance. After an initial adaptation period, the COD removal efficiency stabilized at $74 \pm 5 \%$. From 181 to $200 \mathrm{~d}$, the influent concentration of tetracycline antibiotics increased to $47.50 \mathrm{mg} / \mathrm{L}$. During this period, the COD removal rate dropped continuously and reached its lowest on day 186, with a removal rate of $52 \%$. After day 186 , the COD removal rate increased to $83 \%$ on day 200 . When the tetracycline antibiotic concentration increased to $63.33 \mathrm{mg} / \mathrm{L}$, the COD removal efficiency stabilized at $75 \pm 3 \%$ after several days of adaptation. Ultimately, the influent concentration of tetracycline antibiotics was as high as $95.00 \mathrm{mg} / \mathrm{L}$. The COD removal rate gradually increased to $78 \pm 4 \%$ after a sharp decrease. These results might be due to the adaptation to tetracycline antibiotics in the corresponding fraction of the biomass. Previous studies on erythromycin have made a similar hypothesis. Amin et al. [21] reported that long-term exposure to erythromycin resulted in an adaptation that could be caused either by the development of resistance in existing bacteria or by an increase in the abundance of resistant populations.

The effluent from the UASB was the influent of $\mathrm{A} / \mathrm{O}$. When the influent concentration of tetracycline antibiotics was increased in the UASB, fluctuations in the influent COD concentration were observed, but the COD removal efficiency of the $\mathrm{A} / \mathrm{O}$ reactor was not affected by the influent (Fig. 2(b)). This result demonstrates that the increase in tetracycline antibiotics had no significant effect, and the $\mathrm{A} / \mathrm{O}$ reactor showed high tolerance to tetracycline antibiotic wastewater. The COD removal rate of the UASB-A/O reactor remained above $90 \%$ during the experiment, indicating the practicability of the UASB-A/O reactor with a high influent tetracycline antibiotic concentration.

\subsubsection{Tetracycline antibiotics removal of the UASB and $A / 0$ reactor} Statistical analysis (Fig. 3) revealed that the removal rate of tetracycline antibiotics in the UASB-A/O reactor. The influent concentration of tetracycline antibiotics increased to $47.50 \mathrm{mg} / \mathrm{L}$, the tetracycline antibiotics removal rate of the UASB and A/O reactor dropped continuously and reached its lowest on day 186, and the removal rate increased to $93 \%$ on day 200 . When the tetracycline antibiotic concentration increased to $63.33 \mathrm{mg} / \mathrm{L}$ and $95 \mathrm{mg} / \mathrm{L}$, the tetracycline antibiotics removal was gradually stable after a sharp decrease. As the influent concentration of tetracycline antibiotics increased from 38.00 to $47.5 \mathrm{mg} / \mathrm{L}$, the removal rate of tetracycline antibiotics in the UASB-A/O reactor was at $90.5 \pm 2.5 \%$. As the influent concentration of tetracycline antibiotics increased from 63.3 to $95 \mathrm{mg} / \mathrm{L}$, the removal rate of tetracycline antibiotics in the UASB-A/O reactor decreased to $88.4 \pm 2.5 \%$. Degradation trend of tetracycline was consistent with COD removal trend in the UASB-A/O reactor.

This decrease could be attributed to the physical sorption of aerobic activated sludge, biodegradation of microbial communities, and photo degradation [22-25]. Sungpyo Kim et al. [26] suggested that sorption is the primary mechanism for tetracycline removal instead of biodegradation. Gao et al. [27] reported that $63 \%$ of antibiotics were removed during the secondary biological treatment, which could be attributed to potential biodegradation because sorption to the sludge was minimal. Photo degradation is one of the principal transformation reactions of tetracyclines in the environment. Based on these observations, the UASB and A/O reactors showed stable and efficient performance in treating tetracycline antibiotic wastewater with efficient COD and tetracycline antibiotic removal.

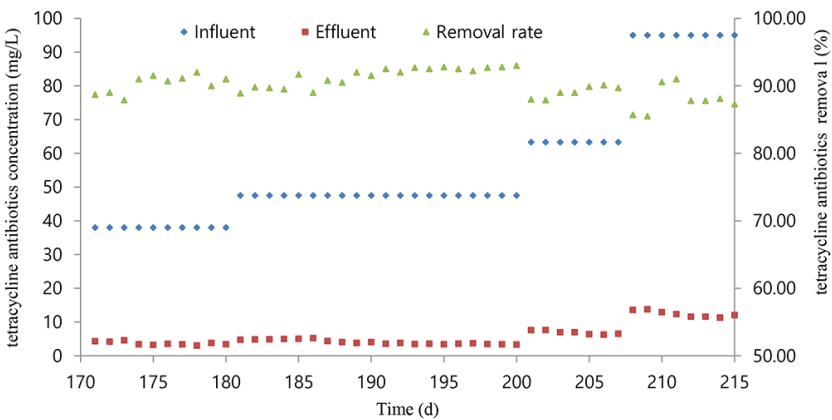

Fig. 3. Tetracycline antibiotics removal of the UASB and A/O reactor.

\subsubsection{Methane production rate and VFA}

The methane production rate was indicative of the operational efficiency of the UASB reactor. Monitoring the composition of the VFAs in the effluent process provided direct and immediate 
information on the inhibitory impact of tetracycline antibiotic wastewater on the anaerobic microorganisms and methane production rate under anaerobic conditions. Fig. 2(c) and Fig. 2(d) show the methane production rate and VFAs measured in the effluent of the UASB reactor. Methane production decreased from 0.50 to $0.30 \mathrm{~L} / \mathrm{g}$ COD with the tetracycline antibiotics concentration changing from 38 to $95.00 \mathrm{mg} / \mathrm{L}$, which illustrated that the inhibitory effect on methane production was increased gradually. Significant inhibition started from $47.50 \mathrm{mg} / \mathrm{L}$ and was maintained until the end of the experiment. VFA accumulation followed a similar trend to methane production inhibition. VFA accumulation was observed when the tetracycline antibiotic concentration was $47.50 \mathrm{mg} / \mathrm{L}$ and increased with the addition of tetracycline antibiotics. High VFA accumulation demonstrated that anaerobic microorganisms were inhibited by tetracycline antibiotic wastewater.

\subsection{Toxicity and Inhibition of Tetracycline on Anaerobic Microorganism}

\subsubsection{Toxicity of tetracycline on anaerobic microorganism}

The cumulative methane production in the intermittent anaerobic biological treatment test reflects the biodegradability of the subjects under anaerobic conditions; that is, the degree of inhibition or toxicity of the tested substances to the anaerobic biological treatment system can be explained. The degree of inhibition of anaerobic organisms was determined by comparing the cumulative methane production of the experimental and blank samples. Relative activity (RA) can be expressed by the following formula [28]:

$$
\mathrm{RA}=\frac{\mathrm{V}_{\mathrm{t}}}{\mathrm{V}_{\mathrm{o}}}
$$

Where $V_{t}$ is the cumulative methane production of the sample at time $t$, and $V_{0}$ is the control cumulative methane production at time $\mathrm{t}$.

To further reveal the inhibition level of methane production and VFA accumulation at different tetracycline antibiotic concentrations, SMA experiments were conducted to characterize the methanogenic activity of anaerobic sludge, and the corresponding results are summarized in Fig. 4. As shown in Fig. 4, methane production decreases with increasing tetracycline concentration, illustrating that tetracycline is an antibiotic with an inhibitory impact on anaerobic microorganisms. Tetracycline may influence the integration of microorganisms with the substrate or inhibit specific enzymatic reactions, leading to the breakdown of the conversion of substrate into methane by microorganisms.

As shown in Fig. 4, the cumulative methane gas production in the four groups was smaller than that in the blank test. With an increase in tetracycline concentration, methane production gradually decreased. This showed that tetracycline inhibits anaerobic organisms, and with an increase in concentration, the degree of inhibition increased. The RA of the four groups were 85.02, 44.82, 15.70, and $4.90 \%$, respectively. The results indicated mild inhibition at $50 \mathrm{mg} / \mathrm{L}$, moderate inhibition at $200 \mathrm{mg} / \mathrm{L}$, and severe inhibition at $400 \mathrm{mg} / \mathrm{L}$ and $600 \mathrm{mg} / \mathrm{L}$ concentrations. With different concentrations of tetracycline hydrochloride, the amount of methane produced by anaerobic organisms decreased by $24.90,45.20,50.80$, and $72.00 \%$ compared with the control group at 50, 200, 400 and

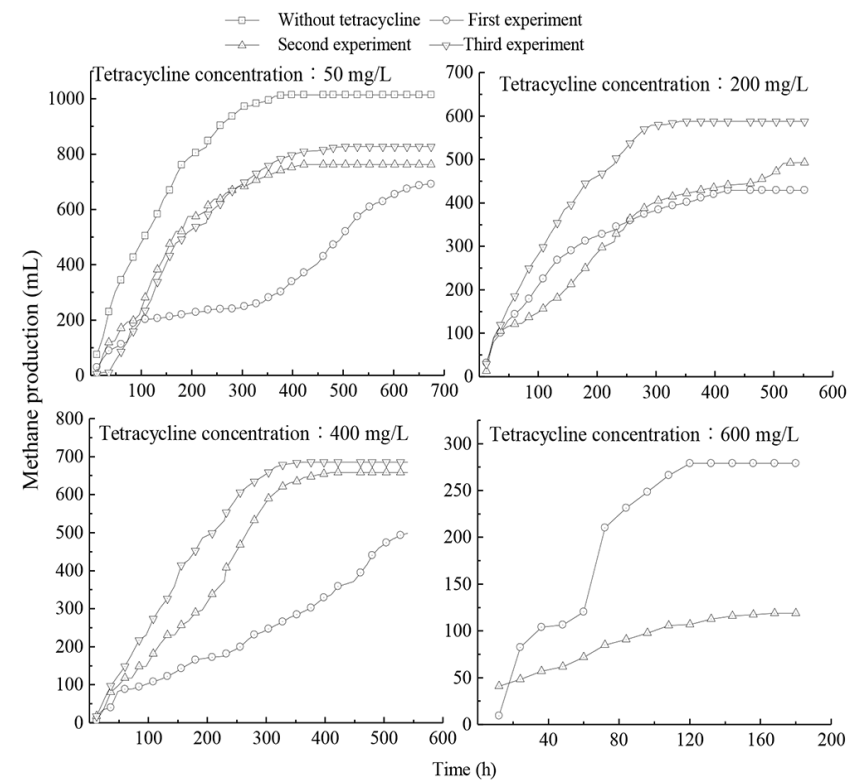

Fig. 4. The methane production at the different tetracycline concentrations.

$600 \mathrm{mg} / \mathrm{L}$, respectively. It has been suggested that chemical interfering substances interfere with specific enzymatic steps in related metabolic reactions, resulting in the conversion of only part of the matrix into methane [29-32]. At $600 \mathrm{mg} / \mathrm{L}$, the gas production of tetracycline hydrochloride decreased gradually with the prolongation of reaction time, which was due to the severe inhibition of anaerobic organisms when the tetracycline concentration reached $600 \mathrm{mg} / \mathrm{L}$. This phenomenon illustrated that adaptation/resistance mechanisms in the corresponding fraction of the biomass were established as time progressed, and the anaerobic activated sludge could biodegrade the tetracycline antibiotic wastewater by chronic acclimatization. It is worth noting that the adverse effect of tetracycline dosing at $600 \mathrm{mg} / \mathrm{L}$ inflicted lethal and non-reversible damage to anaerobic microorganisms inhibited methane generation. Shi et al. [33] and Xia et al. [34] suggested that the removal of tetracycline antibiotics in biological treatment mainly depends on adsorption and biodegradation, but over a short period, it mainly depends on adsorption. With an increase in test duration, the increase in sludge adsorption antibiotics over a short period of time may produce more severe inhibition of anaerobic microorganisms, resulting in duction in methane production.

\subsubsection{Recovery experiment of specific methanogenic activity}

A recovery experiment of specific methanogenic activity was conducted to observe the residual activity of anaerobic activated sludge. The results (Fig. 5) showed that the methane production of the experimental groups with different concentrations of antibiotics was lower than that of the control group, further demonstrating that antibiotics have an inhibitory impact on anaerobic microorganisms. Both oxytetracycline and tetracycline nearly recovered to normal levels at a concentration of $50 \mathrm{mg} / \mathrm{L}$, suggesting that antibiotics slightly inhibited anaerobic microorganisms at low concentrations, which were achieved by inhibiting the metabolism of anaerobic microorganisms. When the antibiotic concentration increased to $600 \mathrm{mg} / \mathrm{L}$, the methane production recovery experiment almost failed, illustrating that high antibiotic concentration killed 


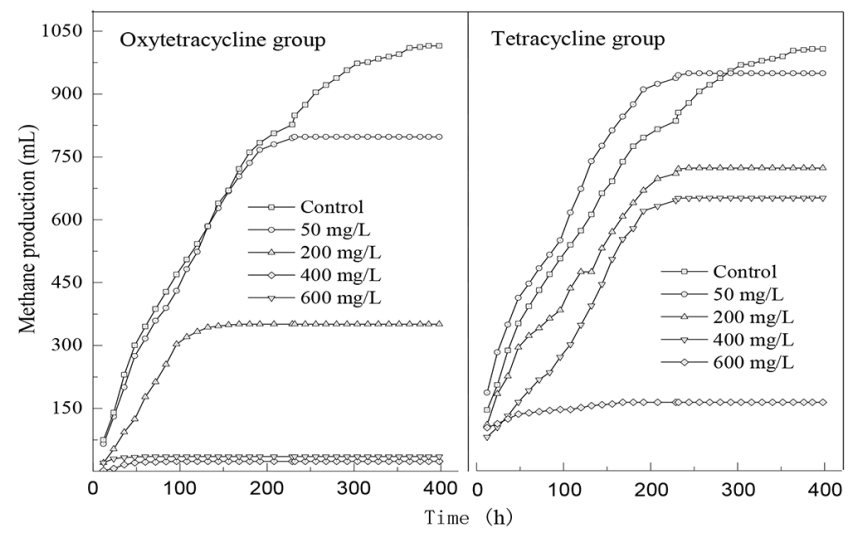

Fig. 5. The methane production at different concentrations of antibiotics.

the methanogenic bacteria and caused unrecoverable influence. This result is similar to that of a previous study on the acute inhibitory impact of sulfamethoxazole, erythromycin, and tetracycline on acetoclastic methanogenic activity [35]. It is worth noting that the lethal concentration of oxytetracycline for anaerobic microorganisms was much lower than that of tetracycline.

\subsubsection{Analysis of VFA}

The conversion of organics to methane originated from the complex metabolic interactions between anaerobic microorganisms in the UASB reactor. As shown in Fig. 6, VFA accumulation increased with increasing antibiotic concentration from $50 \mathrm{mg} / \mathrm{L}$ to $600 \mathrm{mg} / \mathrm{L}$. Moreover, VFA accumulation generated by tetracycline was lower than that generated by oxytetracycline. This result followed a similar trend to the inhibition of methane production. The observations also indicated that when 50 to $600 \mathrm{mg} / \mathrm{L}$ of antibiotic was added, acetic acid, propanoic acid, and n-butyric acid accumulation in the system began and increased. Acetic acid and propanoic acid became important intermediates when tetracycline and oxytetracycline, respectively, were added at $600 \mathrm{mg} / \mathrm{L}$. Stone et al. [36] reported that VFA accumulation, including acetate, butyrate, and propionate, was more significant with the addition of chlortetracycline. Shimada et al. [37] investigated the degradation of acetate and butyrate using grampositive beta-oxidizing syntrophic bacteria (e.g., Syntrophomonas

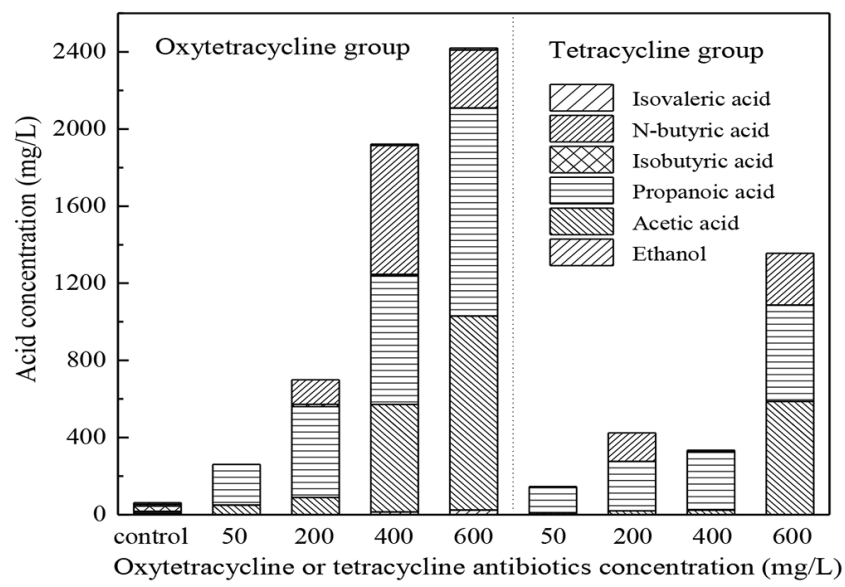

Fig. 6. VFA accumulation at different concentrations of antibiotics. spp. and Syntrophospora spp.) and homoacetogenic bacteria, respectively. Tetracycline and oxytetracycline may inhibit the activity of gram-positive beta-oxidizing syntrophic bacteria and homoacetogenic bacteria. Acetic acid, propanoic acid, and n-butyric acid accounted for more than $90 \%$ of VFA, which indicated that the conversion of short-chain fatty acids to methane could be a critical pathway involved in SMA.

\subsection{Analysis of Anaerobic Sludge Granules}

Sludge granules are the key factor that sustains the efficient and steady operation of anaerobic systems [38]. The development of granules is generally accompanied by a change in the physicochemical characteristics that influence the treatment efficiency of UASB reactors [39]. During the experiment, anaerobic sludge granules in the UASB reactor were monitored on days 24, 140, and 184.

Fig. 7 shows the variations of mean granule size in the UASB reactor during the study. The mean granule diameter in the reactor showed a gradual and progressive change. On day 24 of operation, small and massive granules with diameters of 0-300 $\mu \mathrm{m}$ became visible in the UASB reactor and began to grow during acclimation and pre-granulation. These granules grew rapidly, and after operation for $116 \mathrm{~d}$, the mean granules diameters extended to 300-1500 $\mu \mathrm{m}$. Rapid granulation was mainly due to increasing growth under the high organic loading and F/M ratios applied. JK Jhung et al. [40] reported that with the development of granulation, the applicable organic loading rates were increased for the UASB reactor. During the investigation, anaerobic sludge blanket operated well with the

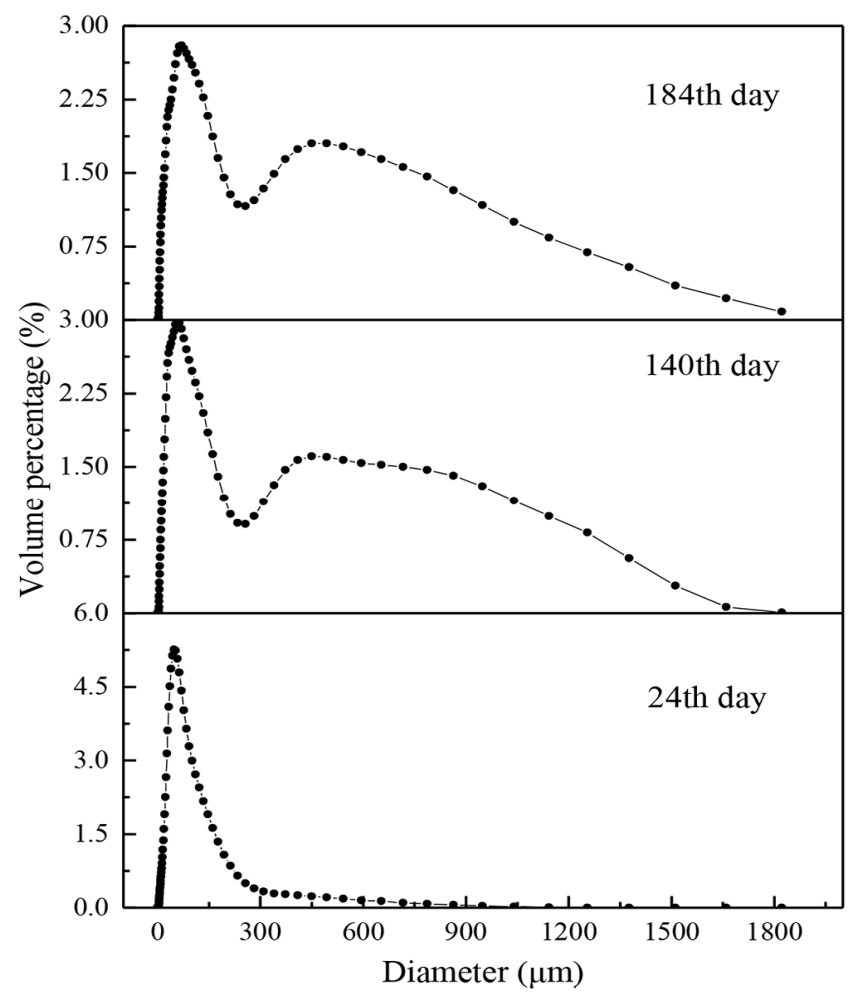

Fig. 7. Anaerobic sludge granules in the UASB reactor at the 24th, 140th, 184th day. 

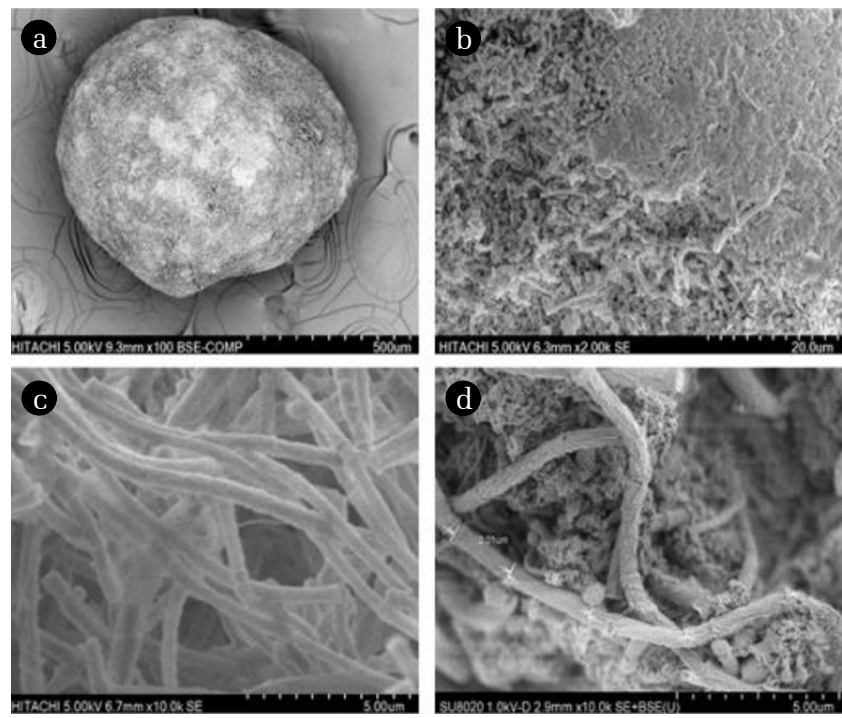

Fig. 8. Electron micrograph of granular sludge (a) anaerobic sludge granules; (b) surface of anaerobic sludge granules;(c) and (d) internal space of anaerobic sludge granules.

granule diameter increased steadily, interpreting that the UASB reactor had superior resistant for tetracycline antibiotics wastewater.

SEM observation was performed for granules obtained from the bottom of the UASB reactor, and these granules were collected during the late period of the experiment. The sludge granules were elliptical with a rough surface (Fig. 8(a)). The existence of rod-shaped and coccus-shaped organisms with pores and internal channels at the granule surface was observed by SEM (Fig. 8(b)). Kim et al. [41, 42] observed similar phenomena, suggesting that pores or internal channels on the surface may be involved in the efficient transfer of substrate and the release of carbon dioxide by microbial metabolic processes within the granules. SEM images showed that the granules were dominated by Methanosaeta-like microbes. In the internal space, methanogenic filamentous bacteria constituted a rock-steady structure intertwined with one another (Fig. 8(c)-(d)). The spaghetti theory was applicable to explain these findings, according to which the filamentous microorganisms first form a frame, a network or nuclei, and other bacteria, such as cocci, were later trapped in the network or attached to the nuclei later, and consequently, granules were formed [43, 44]. Anaerobic sludge granules maintained a rock-steady structure in the later period of the experiment, indicating that the microorganism community could adapt to the high concentration of tetracycline antibiotics, and the UASB reactor could biodegrade the tetracycline antibiotic wastewater.

\section{Conclusions}

The SMA test showed that low concentrations of tetracycline antibiotics $(<50 \mathrm{mg} / \mathrm{L}$ ) had little influence on microorganisms. However, when the concentration was increased above $400 \mathrm{mg} / \mathrm{L}$, the microorganisms were killed by tetracycline antibiotics. The methane production of the UASB reactor achieved a $0.32 \mathrm{~L} / \mathrm{g}$ COD. Although VFA accumulation was observed with the increased concentration of tetracycline antibiotics, the UASB-A/O reactor still operated steadily. After operation for $215 \mathrm{~d}$, the UASB and A/O reactors successfully treated the tetracycline antibiotic wastewater. The COD and tetracycline antibiotic removal rates of the UASB-A/O reactor exceeded $90 \%$. The sludge granule diameter increased from 0-300 $\mu \mathrm{m}$ to $300-1,500 \mu \mathrm{m}$ during the operation. Anaerobic sludge granules maintained a rock-steady structure, suggesting that the microorganism community could adapt to high tetracycline antibiotics concentrations.

\section{Acknowledgment}

This work was supported by the key technologies R \& D program of Tianjin (NO.16ZXGTSF00090), Tianjin Research Program of Application Foundation and Advanced Technology (NO.16JCZDJC 39800) and Major Science and technology innovation engineering projects of Shandong Province (NO.2019JZZY020704).

\section{Author Contributions}

J.F.Z (Ph.D. student) conducted all the experiments and wrote the manuscript. G.Y.C. (Professor) guided the experiments and revised the manuscript. Q.Z. (Professor) conducted specific methanogenic activity experiments. Y.L. (Professor) revised the manuscript. S.Y.Q. (Professor) guided the experiments, wrote and revised the manuscript.

\section{References}

1. Krzeminski P, Tomei MC, Karaolia P, et al. Performance of secondary wastewater treatment methods for the removal of contaminants of emerging concern implicated in crop uptake and antibiotic resistance spread: A review. Sci. Total Environ. 2019;648:1052-1081.

2. Hou J, Chen ZY, Gao J, et al. Simultaneous removal of antibiotics and antibiotic resistance genes from pharmaceutiacal wastewater using the combinations of up-flow anaerobic sludge bed, anoxic-oxic tank, and advanced oxidation technologies. Water Res. 2019;159:511-520.

3. Pu CJ, Yu Y, Diao JX, Gong XY, Li J, Sun Y. Exploring the persistence and spreading of antibiotic resistance from manure to biocompost, soils and vegetables. Sci. Total Environ. 2019;688:262-269.

4. Chen Z, Wang H, Ren N, Cui M, Nie S, Hu D. Simultaneous removal and evaluation of organic substrates and NH3-N by a novel combined process in treating chemical synthesis-based pharmaceutical wastewater. Hazard. Mater. 2011;197:49-59.

5. Zhao FZ, Ju F, Huang KL, et al. Comprehensive insights into the key components of bacterial assemblages in pharmaceutical wastewater treatment plants. Sci. Total Environ. 2019;651: 2148-2157.

6. Matos M, Pereira MA, Parpot P, Brito AG, Nogueira R. Influence of tetracycline on the microbial community composition and activity of nitrifying biofilms. Chemosphere 2014;117:295-302.

7. Gao Y, Li Y, Zhang L, et al. Adsorption and removal of tetracy- 
cline antibiotics from aqueous solution by graphene oxide. J. Colloid Interf. Sci. 2012;368:540-546.

8. Huang MH, Qi FF, Wang J, Xu Q, Lin L. Changes of bacterial diversity and tetracycline resistance in sludge from AAO systems upon exposure to tetracycline pressure. J. Hazard. Mater. 2015;98:303-309.

9. Chopra I, Roberts M. Tetracycline antibiotics mode of action, applications, molecular biology, and epidemiology of bacterial resistance. Microbiol. Mol. Biol. Rev. 2001;65(2):232-260.

10. Zhang W, Huang MH, Qi FF, Sun PZ, Van Ginkel SW. Effect of trace tetracycline concentrations on the structure of a microbial community and the development of tetracycline resistance genes in sequencing batch reactors. Bioresour. Technol. 2013;150:9-14.

11. Qiu GL, Song YH, Zeng P, Duan L, Xiao SH. Combination of upflow anaerobic sludge blanket (UASB) and membrane bioreactor (MBR) for berberine reduction from wastewater and the effects of berberine on bacterial community dynamics. $J$. Hazard. Mater. 2013;246-247:34-43.

12. Han Y, Guo JB, Zhang YY, et al. Anaerobic granule sludge formation and perchlorate reduction in an up-flow anaerobic sludge blanket (UASB) reactor. Bioresour. Technol. Reports. 2018;4:123-128.

13. AkbarpourToloti A, Mehrdadi N. Wastewater Treatment from antibiotics plant (UASB Reactor). Int. J. Environ. Res. 2011;5: 241-246.

14. Coskun T, Kabuk HA, Varinca KB, Debik E, Kavurt C. Antibiotic Fermentation broth treatment by a pilot upflow anaerobic sludge bed reactor and kinetic modeling. Bioresour. Technol. 2012;121:31-35.

15. Qiu GL, Song YH, Zeng P, Duan L, Xiao SH. Characterization of bacterial communities in hybrid upflow anaerobic sludge blanket (UASB)- membrane bioreactor (MBR) process for berberine antibiotic wastewater treatment. Bioresour. Technol. 2013;142:52-62.

16. Sponza DT. Simultaneous granulation, biomass retainment and carbon tetrachloride (CT) removal in an upflow anaerobic sludge blanket (UASB) reactor. Process Biochem. 2002;37:1091-1101.

17. Lu XQ, Ni J, Zhen GY, Kubota K, Li YY. Response of morphology and microbial community structure of granules to influent $\mathrm{COD} / \mathrm{SO}_{4}{ }^{2-}$ ratios in an upflow anaerobic sludge blanket (UASB) reactor treating starch wastewater. Bioresour. Technol. 2018;56:456-465.

18. Carrillo-Reyes J, CelisLB, Alatriste-Mondragon F, Razo-Flores E. Decreasing methane production in hydrogenogenicUASB reactors fed with cheese whey. Biomass Bioenerg. 2014;63: 101-108.

19. Speece RE. Anaerobic Biotechnology for industrial wastewaters. Environ. Sci. Technol. 1983;17(9):416A-427A.

20. APHA, AWWA, WEF. Aggregate organic constituents. Standard Methods for the Examination of Water and Wastewater. 22 ed. APHA, Washington, DC, USA; 2012. p. 14-18.

21. Amin MM, Zilles JL, Greiner J, Charbonneau S, Raskin L, Morgenroth E. Influence of the antibiotic erythromycin on anaerobic treatment of a pharmaceutical wastewater. Environ. Sci. Technol. 2006;40:3971-3977.

22. Zhou P, ASCE M, Su CY, Li BW. Treatment of high-strength pharmaceutical wastewater and removal of antibiotics in anaerobic and aerobic biological treatment processes. J. Environ. Eng. 2006;132:129-136.

23. Prado N, Ochoa J, Amrane A. Biodegradation and biosorption of tetracycline and tylosin antibiotics in activated sludge system. Process Biochem. 2009;44:1302-1306.

24. Godos I, Muñoz R, Guieysse B. Tetracycline removal during wastewater treatment in high-rate algal ponds. J. Hazard. Mater. 2012;229:446-449.

25. Cetecioglu Z, Ince B, Gros M, et al. Chronic impact of tetracycline on the biodegradation of an organic substrate mixture under anaerobic conditions. Water Res. 2013;47:2959-2969.

26. Kim S, Eichhorn P, Jensen JN, Weber AS, Aga DS. Removal of antibiotics in wastewater: effect of hydraulic and solid retention times on the fate of tetracycline in the activated sludge process. Environ. Sci. Technol.2005;39:5816-5823.

27. Gao P, Ding YJ, Li H, Xagoraraki I. Occurrence of pharmaceuticals in a municipal wastewater treatment plant: Mass balance and removal processes. Chemosphere 2012;88:17-24.

28. Young JC, Tabak HH. Multilevel protocol for assessing the fate and effect of toxic organic chemicals in anaerobic treatment processes. Water Environ. Res. 1993;65(1):34-45.

29. Xu SN, Zhang L, Huang SL, Zeeman G, Rijnaarts H, Liu Y. Improving the energy efficiency of a pilot-scale UASB-digester for low temperature domestic wastewater treatment. Biochem. Eng. J. 2018;135:71-78.

30. Chen R, Jiang HY, Li YY. Caffeine degradation by methanogenesis: Efficiency in anaerobic membrane bioreactor and analysis of kinetic behavior. Chem. Eng. J. 2018;334:444-454.

31. Driessen W, Tielbaard M, Vereijken T. Experience on anaerobic treatment of distillery effluent with the UASB process. Water Sci. Technol. 1994;30(12):193-201.

32. Fountoulakis MS, Stamatelatou K, Lyberatos G. The effect of pharmaceuticals on the kinetics of methanogenesis and acetogenesis. Bioresour. Technol. 2008;99(15):7083-7090.

33. Shi YJ, Wang XH, Qi Z, et al. Sorption and biodegradation of tetracycline by nitrifying granules and the toxicity of tetracycline on granules. J. Hazard. Mater. 2011;191(1):103-109.

34. Xia SQ, Jia RY, Feng F, et al. Effect of solids retention time on antibiotics removal performance and microbial communities in an A/O-MBR process. Bioresour. Technol. 2012;106:36-43.

35. Cetecioglu Z, Ince B, Orhon D, Ince O. Acute inhibitory impact of antimicrobials on acetoclastic methanogenic activity. Bioresour. Technol. 2012;114:109-116.

36. Stone JJ, Clay SA, Zhu ZW, Wong KL, Porath LR, Spellman GM. Effect of antimicrobial compounds tylosin and chlortetracycline during batch anaerobic swine manure digestion. Water Res. 2009;43:4740-4750.

37. Cheng DL, Ngo HH, Guo WS, et al. Problematic effects of antibiotics on anaerobic treatment of swine wastewater Author links open overlay panel. Bioresour. Technol. 2018;263:642-653.

38. Li Y, Zhang YB, Xu ZB, Quan X. Chen S. Enhancement of sludge granulation in anaerobic acetogenesis by addition of nitrate and microbial community analysis. Biochem. Eng. J. 2015;95:104-111.

39. Song YX, Liao Q, Yu C, Xiao RY, Tang CJ, Chai LY. Physicochemical and microbial properties of settled and floating 
anammox granules in upflow reactor. Biochem. Eng. J. 2017;123:75-85.

40. Jhung JK, Cho EA. Comparative study of UASB and anaerobic fixed film reactors with development of sludge granulation. Water Res. 1995;29:271-277.

41. Abbasi T, Abbasi SA. Formation and impact of granules in fostering clean energy production and wastewater treatment in upflow anaerobic sludge blanket (UASB) reactors. Renew. Sust. Energ. Rev. 2012;16(3):1696-1708.

42. Kim DH, Lee MK, Moon C, et al. Effect of hydraulic retention time on lactic acid production and granulation in an up-flow anaerobic sludge blanket reactor. Bioresour. Technol. 2014;165: 158-161.

43. Sudmailis D, Millah SK, Gagliano MC, et al. The potential of osmolytes and their precursors to alleviate osmotic stress of anaerobic granular sludge. Water Res. 2018;147:142-151.

44. Zhou WL, Imai T, Ukita M, Sekine M, Higuchi T. Triggering forces for anaerobic granulation in UASB reactors. Process Biochem. 2006;41:36-43. 